\title{
Pilot-scale treatment of waste-water from carbon production by a combined physical-chemical process
}

\author{
Hongjie Wang, ${ }^{a, b}$ Ruiping Liu, ${ }^{a}$ Jiuhui $Q u,{ }^{a *}$ Maohong Fan ${ }^{\mathrm{c}}$ and \\ Huaizheng $\mathbf{L i}^{d}$
}

\begin{abstract}
BACKGROUND: Due to its strong colour, high concentrations of fluorides and chemical oxygen demand (COD $\left.\mathrm{Cr}_{\mathrm{r}}\right)$ and large amount of suspended solids (SS), the waste-water from carbon production (WCP) seriously affects the stability of the circulating system of Guizhou Branch, Aluminium Corporation of China. In this paper, the performance of a pilot-scale (24 $\mathrm{m}^{3} \mathrm{~d}^{-1}$ ) combined treatment plant, consisting of chemical precipitation, coagulation, and Fenton oxidation, for the treatment of WCP was investigated.

RESULTS: Lime precipitation and hydrated ferrous sulphate (HFS) coagulation, with polyacrylamide (PAM) as a coagulation aid, proved to be effective in the removal of colour $(>70 \%)$, suspended solids (SS) $(>90 \%)$ and fluoride ( $>80 \%)$ from the WCP. Subsequent Fenton oxidation combined with coagulation as a final treatment efficiently removed $S_{S}, F^{-}$, COD $\mathrm{Cr}_{\mathrm{c}}, \mathrm{dissolved}$ organic carbon (DOC) and colour. The average total removal efficiencies of these parameters in the pilot-scale combined technology were as follows: $\mathrm{SS}=\mathbf{9 8 . 8} \%, \mathrm{~F}^{-}=\mathbf{9 5 . 7 \%}, \mathrm{COD}_{\mathrm{Cr}}=\mathbf{9 4 . 8 \%}, \mathrm{DOC}=\mathbf{9 1 . 8} \%$ and colour $=98.3 \%$, giving an average

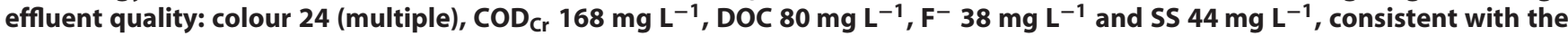
reusable water limits for the process.
\end{abstract}

CONCLUSIONS: The current experimental results and the economic evaluation suggest that the combined process could be advantageous and feasible for the treatment of WCP.

(c) 2009 Society of Chemical Industry

Keywords: waste-water; carbon production (WCP); aluminium smelting; lime precipitation; coagulation; Fenton oxidation; decolouration; fluoride removal

\section{INTRODUCTION}

Water shortage and water pollution are global crises we are facing today. To minimize these problems, some factories that use large amounts of water have taken effective measures to reuse industrial water. The Guizhou Branch of the Aluminium Corporation of China, established an industrial water reuse system $\left(50000 \mathrm{~m}^{3} \mathrm{~d}^{-1}\right)$, in which all of the industrial water is suitably treated, and then reused in different manufacturing processes. Unfortunately, the waste-water from carbon production (WCP) seriously affects the stability of the circulating system due to its strong colour, high concentration of fluorides and chemical oxygen demand $\left(\mathrm{COD}_{\mathrm{Cr}}\right)$ and large amounts of suspended solids (SS).

Carbon, such as pre-baked anodes, is the main auxiliary material for the production of aluminium ingot. During the baking cycles, asphalt fume and fluorides emitted from the pre-baked anode production and sulphur dioxide $\left(\mathrm{SO}_{2}\right)$ produced from heavy oil combustion result in serious environmental problems. Much effort has been taken to treat asphalt fume and to remove fluorides and $\mathrm{SO}_{2} \cdot{ }^{1,2}$ Wet electrostatic collection is the traditional and effective method for purifying asphalt fume. ${ }^{3-5}$ Moreover, wet flue gas desulphurization (WFGD) technology is a well-established process for removing $\mathrm{SO}_{2}$. The Guizhou Branch of the Aluminium
Corporation of China uses a wet electrostatic collection process. The waste-water produced from the wet scrubbers contains appreciable quantities of fluorides, metallic ions and organic compounds and so is not easily amenable to chemical or biological treatment. ${ }^{6}$ Moreover, because the WCP is circulated many times, it exhibits an intense dark colour (over 2000 multiples), high SS, high concentration of dissolved salts and highly fluctuating $\mathrm{pH}$ $(6-10)$. Due to the complexity of the WCP, any single treatment

\footnotetext{
* Correspondence to: Jiuhui Qu, Research Centerfor Eco-Environmental Sciences, Chinese Academy of Sciences, Beijing 100085, China.

E-mail:jhqu@rcees.ac.cn

a Research Center for Eco-Environmental Sciences, Chinese Academy of Sciences, Beijing 100085, China

b Graduate University of the Chinese Academy of Science, Beijing 100049, China

c School of Energy Resources and Department of Chemical \& Petroleum Engineering of University of Wyoming Laramie, WY 82071, USA; and School of Civil and Environmental Engineering of Georgia Institute of Technology, Atlanta, GA 30332, USA
}

d Shanghai Academy of Environmental Science, Shanghai, 200233 China 
method would be inadequate, and to date literature regarding WCP treatment has been scarce.

To meet the permitted value for reuse of WCP, it is necessary to develop cost-effective processes to remove the $\mathrm{F}^{-}$, $\mathrm{COD}_{\mathrm{Cr}}$, SS and colour. Generally, there are several methods for removing fluoride, such as membrane, adsorption, chemical precipitation, and electrochemical coagulation. ${ }^{7-13}$ When the fluoride concentration is high, chemical precipitation of $\mathrm{CaF}_{2}$ by the addition of calcium salt, such as $\mathrm{CaCl}_{2}$ is commonly used. ${ }^{12}$ However, the introduction of $\mathrm{Cl}^{-}$would inevitably cause the severe corrosion of metallic pipelines and other equipment. The addition of lime or calcium hydroxide is a practical alternative to avoid this problem. ${ }^{13}$ Additionally, the formation of fine $\mathrm{CaF}_{2}$ particles during precipitation increases the requirement for solid-liquid separation. Aluminium and ferric/ferrous salts, typically used as coagulants following calcium precipitation for the destabilization of $\mathrm{CaF}_{2}$ precipitates, also contributes to the removal of fluoride. The effects of co-precipitation and adsorption reactions may occur in the lime precipitation/coagulation process.

Although chemical precipitation and coagulation are effective in removal of fluoride and SS, they are largely ineffective in removing $\mathrm{COD}_{\mathrm{C}}$, dissolved organic carbon (DOC) and colour. On the other hand Fenton oxidation has been demonstrated to be quite effective in treating different industrial waste-waters. ${ }^{14-24}$ Fenton oxidation tends to destroy the recalcitrant organic chemicals in the waste-water, resulting in the removal of $\mathrm{COD}_{\mathrm{Cr}}, \mathrm{DOC}$ and colour. Unfortunately, it is much too expensive to employ Fenton oxidation directly to treat the raw waste-water. Thus, a novel pilot-scale combined process, consisting of chemical precipitation, coagulation, and Fenton oxidation, was proposed in this study to treat the WCP. The aim was to produce an effluent consistent with the reusable water limits for the carbon works and even for the whole waste-water recycling system of Guizhou Branch of the Aluminium Corporation of China.

\section{MATERIALS AND METHODS}

The research was divided into two experimental phases. The first phase was laboratory studies including raw waste-water analysis, the optimization of lime precipitation and coagulation, the effect of $\mathrm{Fe}^{2+}$ and $\mathrm{H}_{2} \mathrm{O}_{2}$ dosage on $\mathrm{COD}_{\mathrm{Cr}}$ removal, etc. Based on the laboratory results, in the second phase a pilot-scale system was constructed and was operated for two months to obtain the optimum parameters for the waste-water treatment engineering of WCP.

\section{Materials}

Hydrated ferrous sulphate $\left(\mathrm{FeSO}_{4} \cdot 7 \mathrm{H}_{2} \mathrm{O}, \mathrm{HFS}\right)$, ferric chloride $\left(\mathrm{FeCl}_{3}\right)$, poly-aluminium chloride $(\mathrm{PACl})$, hydrogen peroxide $\left(\mathrm{H}_{2} \mathrm{O}_{2}\right.$, $30 \% \mathrm{w} / \mathrm{w})$, polyacrylamide (PAM), sulphuric acid $(95 \%, \mathrm{w} / \mathrm{w})$, calcium chloride $\left(\mathrm{CaCl}_{2}\right)$ and lime $(\mathrm{CaO})$ of commercial grade were utilized in the experiments. Lime was prepared in the form of slurry $(10 \%, w / w)$. HFS was also prepared as a $10 \%(w / w)$ solution and PAM as a $1 \% 0(\mathrm{w} / \mathrm{w})$ solution.

\section{Batch experiments}

To investigate the behaviour of fluoride removal by lime, experiments were performed in a $1 \mathrm{~L}$ conical flask. Appropriate amounts of lime slurry $(10 \%, \mathrm{w} / \mathrm{w})$ were added to the WCP and the slurries were continuously mixed with a Teflon-coated magnetic stirrer bar at room temperature $\left(25 \pm 0.5^{\circ} \mathrm{C}\right)$. After the reaction, small samples (typically $10 \mathrm{~mL}$ ) were taken, filtered through a $0.45 \mu \mathrm{m}$ membrane syringe filter, and analysed for fluoride.

Coagulation tests were performed using a Phipps and Bird sixpaddle stirrer. HFS with PAM was used as coagulant. The procedure consisted of a $1 \mathrm{~min}$ rapid mix (200 rpm), 15 min slow mix (30 rpm), and a 30 min settling period. The $\mathrm{F}^{-}, \mathrm{COD}_{\mathrm{Cr}}, \mathrm{DOC}$, and colour of the water samples were then analysed.

Fenton oxidation experiments were conducted using $30 \% \mathrm{H}_{2} \mathrm{O}_{2}$ and $10 \% \mathrm{FeSO}_{4} \cdot 7 \mathrm{H}_{2} \mathrm{O}$ solutions. The $\mathrm{pH}$ of WCP was adjusted using sulphuric acid $(95 \%, \mathrm{w} / \mathrm{w})$. Then, different dosages of $\mathrm{H}_{2} \mathrm{O}_{2}$ and $\mathrm{FeSO}_{4} \cdot 7 \mathrm{H}_{2} \mathrm{O}$ were added to the $500 \mathrm{~mL}$ samples. Mixing at $120 \mathrm{rpm}$ for $30 \mathrm{~min}$ followed by settling for $30 \mathrm{~min}$ was applied to the samples. After the reaction, lime slurry was added to the system to perform secondary coagulation and sedimentation, and then the $\mathrm{COD}_{\mathrm{Cr}}, \mathrm{DOC}$, and colour of the supernatant water were analysed.

\section{Pilot-scale system description}

Figure 1 shows the schematic diagram of pilot-scale WCP treatment system with capacity of $24 \mathrm{~m}^{3} \mathrm{~d}^{-1}$.

WCP from the sedimentation channel was first homogenized in an equalization tank, and then pumped into the chemical precipitation tank, into which the lime slurry was added by a metering pump. There the precipitation reaction of lime and $\mathrm{F}^{-}$ took place. After that, HFS solution was added to the system and the water was lifted to an inclined-board sedimentation tank. Then, the sludge was pumped into the sludge thickener, and the supernatant was circulated to the washing tower or to the acidified and equalization tank. Following the addition of Fenton reagent, the WCP was then treated by Fenton oxidation. This reaction was terminated by the addition of a lime slurry. Then, secondary coagulation and sedimentation were carried out as a

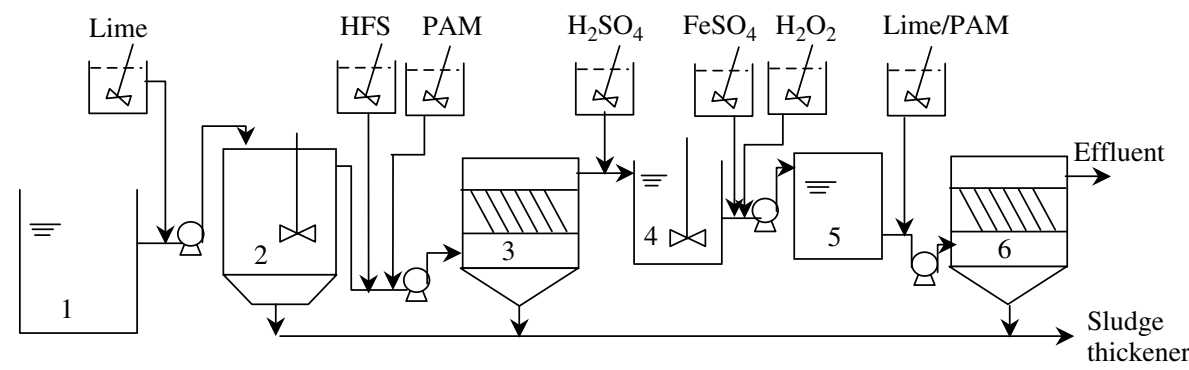

Figure 1. Flow diagram of the pilot-scale WCP treatment system: (1) equalization tank, $V=5 \mathrm{~m}^{3} ;(2)$ chemical precipitation tank, $V=1 \mathrm{~m}^{3} ;(3)$ coagulation and sedimentation tank, $V=1 \mathrm{~m}^{3} ;$ (4) acidification and equalization tank, $V=3 \mathrm{~m}^{3} ;(5)$ oxidation tank, $V=2 \mathrm{~m}^{3}$; (6) second coagulation and sedimentation tank, $V=1 \mathrm{~m}^{3}$. 
final treatment. The main functions and design parameters for each unit are as follows:

- Equalization tank: the effective volume of the equalization tank is approximately $5 \mathrm{~m}^{3}$ and the hydraulic retention time (HRT) about $5 \mathrm{~h}$.

- Chemical precipitation tank: lime slurry $(10 \% \mathrm{w} / \mathrm{w})$ and WCP are pumped into the chemical precipitation tank, and are mixed by a blade stirrer at $30 \mathrm{rpm}$. The effective volume of the chemical precipitation tank is approximately $1 \mathrm{~m}^{3}$ and the HRT is about $1 \mathrm{~h}$.

- Coagulation and sedimentation tank: the effective volume of the sedimentation zone is approximately $1 \mathrm{~m}^{3}$ and the HRT is about $1 \mathrm{~h}$. The coagulants used were hydrated ferrous sulphate $(10 \% \mathrm{w} / \mathrm{w})$ and polyacrylamide (PAM, $1 \%$ ).

- Acidification and equalization tank: the $\mathrm{pH}$ value of the WCP was maintained in the range $3.0 \pm 0.5$ using sulphuric acid $(95 \%$ $\mathrm{w} / \mathrm{w})$ in the acidification and equalization tank. The effective volume of the equalization tank is approximately $3 \mathrm{~m}^{3}$ and the $\mathrm{HRT}$ is about $3 \mathrm{~h}$.

- Oxidation tank: the effective volume of the oxidation tank is approximately $2 \mathrm{~m}^{3}$ and the HRT is about $2 \mathrm{~h}$.

- Secondary coagulation and sedimentation tank: lime slurry was pumped into the effluent from the oxidation tank, and the Fenton oxidation reaction was also terminated. Concurrently, the tank has functions of coagulation, sedimentation, and sludge exclusion. The effective volume of the sedimentation zone is approximately $1 \mathrm{~m}^{3}$ and the HRT is about $1 \mathrm{~h}$.

\section{Analytical methods}

The performance of the combined system was monitored by analysing the parameters: colour, $\mathrm{F}^{-}, \mathrm{COD}_{\mathrm{cr}}, \mathrm{DOC}, \mathrm{SS}, \mathrm{pH}$, and conductivity. All the samples were collected intermittently and analysed during experiments for about 2 months. $\mathrm{COD}_{\mathrm{Cr}}$ was measured using a $\mathrm{COD}_{\mathrm{Cr}}$ meter (Hachi, USA). The DOC concentration in water was measured by a multi N/C 3000 (Analytik Jena AG, Germany). SS was measured using the gravimetric method. The $\mathrm{pH}$ was measured with a digital $\mathrm{pH}$ meter (Hachi, USA). The waste-water colour was determined by the standard dilution multiple method. The UV/Vis spectra were recorded on a U-3010 UV/Vis spectrophotometer (Hitachi Co., Japan) in $10 \mathrm{~mm}$ quartz cuvettes. Conductivity was determined by a DDS-307 digital conductivity meter (Hachi, USA). Fluoride, sulphate/sulphite were determined by an ion chromatograph (Metrohm 861, Switzerland).

\section{RESULTS AND DISCUSSIONS}

\section{Characteristics of WCP}

The waste-water was obtained from the Carbon Plant of the Guizhou Branch, Aluminium Corporation of China located in the south-west of China. The raw water used in the laboratory scale experiments was drawn from the effluent of the sedimentation channel below the washing tower, and its characteristics are presented in Table 1, together with the limits for discharge and reuse in the washing tower. To avoid adverse effects on the quality of the whole industrial water reuse system the discharge limits from Carbon Production require that colour, $\mathrm{F}^{-}, \mathrm{SS}, \mathrm{COD}_{\mathrm{Cr}}$, and DOC of the waste-water should be lower than 100 (multiple), $100 \mathrm{mg} \mathrm{L}^{-1}, 100 \mathrm{mg} \mathrm{L}^{-1}, 200 \mathrm{mg} \mathrm{L}^{-1}$ and $100 \mathrm{mg} \mathrm{L}^{-1}$, respectively. As for the water being recycled to the washing tower, the limits for fluoride and SS should be lower than $500 \mathrm{mg} \mathrm{L}^{-1}$ and $240 \mathrm{mg}$ $\mathrm{L}^{-1}$, respectively.
Table 1. Characteristics of WCP

\begin{tabular}{lccc} 
Parameter & Value & $\begin{array}{c}\text { Reuse limits } \\
\text { for washing } \\
\text { tower }\end{array}$ & $\begin{array}{c}\text { Discharge } \\
\text { limits }\end{array}$ \\
\hline Colour (multiple) & 1460 & - & 100 \\
$\mathrm{SS}\left(\mathrm{mg} \mathrm{L}^{-1}\right)$ & 4200 & 240 & 100 \\
$\mathrm{COD} \mathrm{Cr}^{\mathrm{a}}\left(\mathrm{mg} \mathrm{L}^{-1}\right)$ & 3250 & - & 200 \\
$\mathrm{DOC}\left(\mathrm{mg} \mathrm{L}^{-1}\right)$ & 1180 & - & 100 \\
Sulphate $\left(\mathrm{mg} \mathrm{L}^{-1}\right)$ & 23460 & - & - \\
$\mathrm{F}^{-}\left(\mathrm{mg} \mathrm{L}^{-1}\right)$ & 1370 & 500 & 100 \\
$\mathrm{pH}$ & 10.0 & $>9$ & - \\
Conductivity $\left(\mathrm{mS} \mathrm{cm}^{-1}\right)$ & 41 & - & - \\
\hline
\end{tabular}

${ }^{a}$ Discharge limits for the wastewater from carbon production at the wastewater treatment system of Guizhou Branch of the Aluminium Corporation of China.

Under basic conditions the WCP was observed to exhibit a strong dark colour, that dramatically decolourized under acidic $\mathrm{pH}$ conditions ( $\mathrm{pH}=5.8$ ). After being treated by anion exchange resin, the colour of WCP completely disappeared. The UV/Vis spectrum of the raw WCP $(\mathrm{pH}=10.0)$, acidified $\mathrm{WCP}(\mathrm{pH}=5.8)$ and the anion exchanged WCP $(\mathrm{pH}=13.0)$ were measured. The absorbance of these three samples in the visible light zone $(>400 \mathrm{~nm})$, exhibited no characteristic absorbance peak. In the UV zone (200-400 nm), however, some strong characteristic absorbing peaks appeared at $260 \mathrm{~nm}, 290 \mathrm{~nm}, 332 \mathrm{~nm}$, and $362 \mathrm{~nm}$, indicating the presence of aromatic compounds in WCP. ${ }^{17,25-26}$ These functional groups were the main factor contributing to the dark colour of WCP. Interestingly, the characteristic absorbing peaks mentioned above disappeared in the spectra of the anion exchanged WCP $(\mathrm{pH}=13.0)$, which indicated that the aromatic compounds under basic conditions were mainly anionic species.

\section{Chemical precipitation}

A lime slurry $(10 \%, w / w)$ was proposed to be used as precipitant for the removal of high concentrations of fluoride, and the removal efficiencies of colour and $\mathrm{COD}_{\mathrm{Cr}}$ were also investigated (Fig. 2).

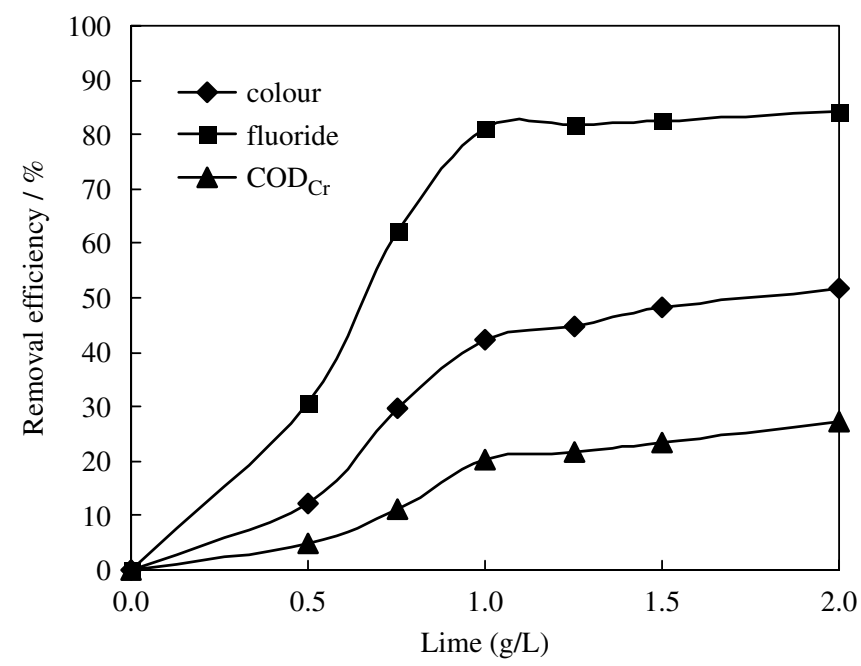

Figure 2. Fluoride, $\operatorname{COD}_{\mathrm{cr}}$ and colour removal efficiency at different lime dosages. 
Lime slurry showed a good capability for removal of fluoride, colour, and $\mathrm{COD}_{\mathrm{Cr}}$, and more significant removal of fluoride was observed. The higher dosage of lime slurry did not lead to corresponding higher removal efficiency of these pollutants when the lime dosage was $>1 \mathrm{~g} \mathrm{~L}^{-1}$. The lime dose at $1 \mathrm{~g} \mathrm{~L}^{-1}$ gave removal efficiencies of $81.1 \%, 42.5 \%$, and $20.2 \%$ for fluoride, colour, and $\mathrm{COD}_{\mathrm{Cr}}$, respectively, with residual concentrations of fluoride $259 \mathrm{mg} \mathrm{L}^{-1}$, colour 840 multiples, and $\mathrm{COD}_{\mathrm{Cr}} 2594 \mathrm{mg}$ $\mathrm{L}^{-1}$. Thus, a lime dose of $1 \mathrm{~g} \mathrm{~L}^{-1}$ was applied in the pilot-scale WCP treatment system.

It was difficult to achieve a low concentration of fluorides through slurry lime precipitation, except by the addition of excess amounts of precipitant (i.e. slurry lime), although the theoretical solubility of fluorite in water $\left(\mathrm{CaF}_{2}\right)$ is $17 \mathrm{mg} \mathrm{L} \mathrm{L}^{-1}$ at $25^{\circ} \mathrm{C}$. $^{12}$ However, with the high concentration of competing anions, the $K_{\mathrm{sp}}$ of $\mathrm{CaF}_{2}$ was modified in the WCP system mainly due to the formation of soluble fluoride complexes and the salt effect. As a result, the solubility of $\mathrm{CaF}_{2}$ is enhanced, with the consequent risk of reduced fluoride removal efficiency. Moreover, with $\mathrm{pH}>9.0$, another problem associated with calcium precipitation was that the particles of $\mathrm{CaF}_{2}$ were too fine to be removed by sedimentation. Consequently, a coagulation unit was necessary.

\section{Coagulation}

$\mathrm{HFS}, \mathrm{FeCl}_{3}, \mathrm{PACl}$ coagulants with PAM were applied to test the capability for WCP coagulation. The results indicated that they were all efficient for the removal of SS, but only contributed to the limited removal of $\mathrm{COD}_{\mathrm{Cr}}$ and $\mathrm{DOC}$ (data not presented). In comparison, HFS exhibited the highest coagulation efficiency, resulting in the highest colour removal at $\mathrm{pH}$ values >9.0. Additionally, HFS avoided the introduction of chloride into the circulating system. Based on this, HFS was chosen as the coagulant. Experiments were run during which HFS was applied at an increasing concentration while the $\mathrm{pH}$ was controlled $>9.0$ by using a lime slurry.

After lime precipitation at a dose of $1 \mathrm{~g} \mathrm{~L}^{-1}$ for $1 \mathrm{~h}$, the combination of HFS and PAM were used as coagulants. As shown in Fig. 3, the removal efficiency of $\mathrm{F}^{-}, \mathrm{COD}_{\mathrm{Cr}}, \mathrm{DOC}$, and colour increased with higher dosages of HFS. For example, HFS at $1000 \mathrm{mg}$ $\mathrm{L}^{-1}$ (with $5 \mathrm{mg} \mathrm{L}^{-1}$ PAM) led to a removal efficiency of $56.8 \%, 23.7 \%$, $25 \%$, and $52.4 \%$ for $\mathrm{F}^{-}, \mathrm{COD}_{\mathrm{Cr}}, \mathrm{DOC}$, and colour, respectively.

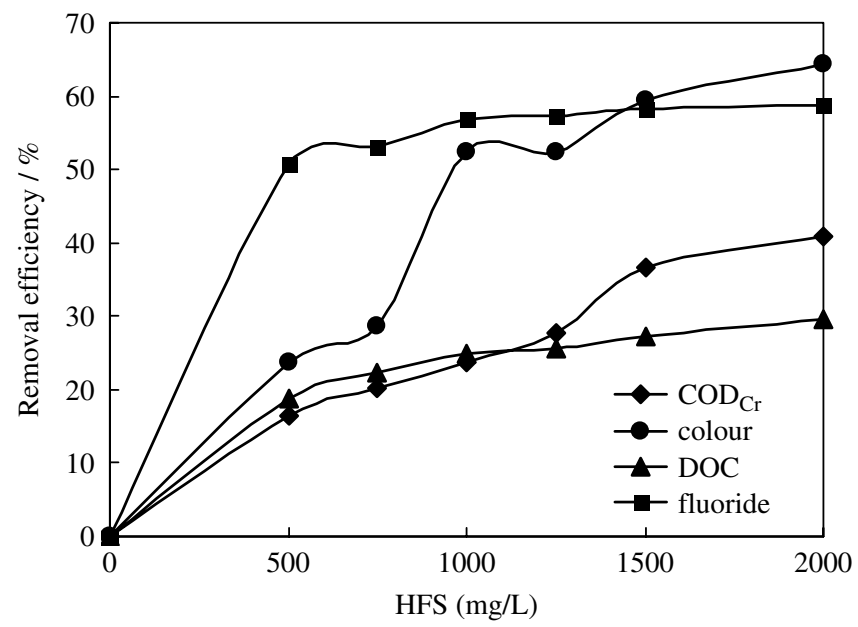

Figure 3. $\mathrm{F}^{-}, \mathrm{COD}_{\mathrm{Cr}}$, DOC and colour removal efficiency at different HFS dosages.
The higher HFS dosages did not contribute significantly to an increase of the removal efficiency for $\mathrm{F}^{-}, \mathrm{COD}_{\mathrm{Cr}}$, $\mathrm{DOC}$ and colour. Considering the problem of sludge treatment, the HFS dosage of $1000 \mathrm{mg} \mathrm{L}^{-1}$ was applied in the pilot-scale WCP treatment processes.

After chemical precipitation and coagulation, the residual effluent concentrations of $\mathrm{F}^{-}, \mathrm{COD}_{\mathrm{Cr}}$, DOC and colour of the WCP were $112 \mathrm{mg} \mathrm{L}^{-1}, 1980 \mathrm{mg} \mathrm{L}^{-1}, 720 \mathrm{mg} \mathrm{L}^{-1}$, and 400 multiples, which corresponded to the total removal efficiency of $91.8 \%, 39.1 \%, 38.9 \%$, and $72.6 \%$. This indicated that the combined process of chemical precipitation and coagulation was promising for fluoride removal. Unfortunately, the $\mathrm{COD}_{\mathrm{Cr}}$, DOC, and colour in the effluent were still above the required standard for the reusing system. Generally, these pollutants were mainly refractory compounds which were difficult to deal with by conventional processes. Advanced oxidation processes (AOPs) may be feasible for further treatment, among which the Fenton oxidation process appeared to be a potential and economical way to eliminate these pollutants. The Fenton oxidation process minimized the introduction of pollutants into the WCP, which were valuable for the stability of the reusing system.

\section{Fenton oxidation and coagulation}

Effect of $\mathrm{pH}$ on the $\mathrm{COD}_{\mathrm{Cr}}$ and colour removal efficiency

The treatment efficiency of Fenton oxidation is highly $\mathrm{pH}$ dependent. ${ }^{15,17}$ It is believe that the $\mathrm{pH}$ value has to be in the acidic range to generate the maximum amount of hydroxyl radicals to oxidize the organic compounds. Research proved that the generation of hydroxyl radicals is slower in $\mathrm{pH}$ values $>4$ because of the formation of ferric-hydroxo complexes. ${ }^{17}$ However, Tekin et al. $^{27}$ report that no significant differences in treatment efficiency were observed within the initial $\mathrm{pH}$ range $3.0-4.5$, so in this study, the removal of $\mathrm{COD}_{\mathrm{Cr}}$ and colour was investigated within the $\mathrm{pH}$ range $2-4.5$. With this $\mathrm{pH}$ range, the removal efficiency of $\mathrm{COD}_{\mathrm{Cr}}$ generally increased to maximum values at $\mathrm{pH}=2.5$, after which there were no significant changes to $\mathrm{pH} 4$, and then the removal efficiency decreased with $\mathrm{pH}$ values $>4$. The optimum $\mathrm{pH}$ range for colour removal was found in the $\mathrm{pH}$ range 3-3.5. Quantitatively, the maximum removal efficiency of $\mathrm{COD}_{\mathrm{Cr}}$ and colour was about $90 \%$ and $95 \%$, respectively.

At low $\mathrm{pH}(\mathrm{pH}<2.5)$, the oxidization ability of Fenton's Reagent is quite poor in destroying the recalcitrant groups within the aromatic compounds. ${ }^{17}$ Consequently, the removal efficiency of $\mathrm{COD}_{\mathrm{Cr}}$ and colour were limited. The removal efficiency started to decrease at $\mathrm{pH} 4$, due to the increasing rate of auto-decomposition of $\mathrm{H}_{2} \mathrm{O}_{2}$, deactivation of iron ion into iron oxyhydroxides, and the increased scavenging effect of ${ }^{\bullet} \mathrm{OH}$ resulting in the decreased oxidation potential of ${ }^{\bullet} \mathrm{OH} .{ }^{18}$ The results showed that high $\mathrm{COD}_{\mathrm{Cr}}$ and colour removal efficiency could only be achieved effectively in a narrow $\mathrm{pH}$ range. It was better to keep the $\mathrm{pH}$ value in the range 2.5-3.5 for the treatment of WCP by Fenton oxidation. The aim in the water treatment process was to optimize the operational conditions to achieve maximum treatment efficiency while minimizing the use of chemicals such as acid and base for pH adjustment. Taking both $\mathrm{COD}_{\mathrm{Cr}}$ and colour removal into consideration, $\mathrm{pH} 3.5$ was chosen for the Fenton reaction in this study.

Effect of $\mathrm{H}_{2} \mathrm{O}_{2}$ dosage on the removal efficiency of $\mathrm{COD}_{\mathrm{Cr}}$ and colour To investigate the treatability and the optimal operational conditions for WCP effluent from the acidification process using Fenton reagent, two sets of experiments were performed on a 


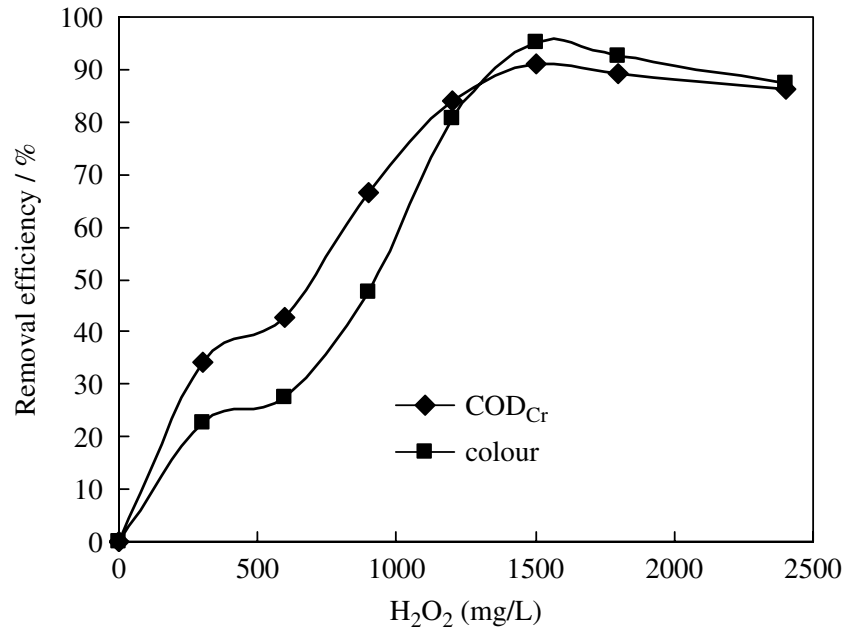

Figure 4. Effect of $\mathrm{H}_{2} \mathrm{O}_{2}$ dosages on $\mathrm{COD}_{\mathrm{Cr}}$ and colour removal efficiency $\left(\mathrm{Fe}^{2+} 184 \mathrm{mg} \mathrm{L}^{-1} ; \mathrm{pH} 3.5\right)$.

laboratory scale to study independently the effect of initial $\mathrm{Fe}^{2+}$ and $\mathrm{H}_{2} \mathrm{O}_{2}$ concentrations at $\mathrm{pH} 3.5$ and room temperature for practical and economic reasons.

Figure 4 shows the removal efficiency of colour and $\mathrm{COD}_{\mathrm{Cr}}$ at different $\mathrm{H}_{2} \mathrm{O}_{2}$ dosages. With the $\mathrm{H}_{2} \mathrm{O}_{2}$ dosage increasing from 300-1500 $\mathrm{mg} \mathrm{L}^{-1}$, the $\mathrm{COD}_{\mathrm{Cr}}$ and colour removal efficiency increased from $34.2-91.2 \%$ and from $22.5-95 \%$, respectively. At higher $\mathrm{H}_{2} \mathrm{O}_{2}$ dosages, the removal of colour and $\mathrm{COD}_{\mathrm{Cr}}$ showed no obvious increase, owing to the scavenging effect of $\mathrm{H}_{2} \mathrm{O}_{2}$ on - $\mathrm{OH}$ radicals, and so the optimum $\mathrm{H}_{2} \mathrm{O}_{2}$ dosage was $1500 \mathrm{mg} \mathrm{L}^{-1}$.

Effect of $\mathrm{Fe}^{2+}$ dosage on the $\mathrm{COD}_{\mathrm{Cr}}$ and colour removal efficiency Figure 5 shows the effect of HFS dosage on $\mathrm{COD}_{\mathrm{Cr}}$ and colour removal efficiency. It was observed that the removal efficiency of $\mathrm{COD}_{\mathrm{Cr}}$ and colour increased with higher $\mathrm{Fe}^{2+}$ dosages, and the maximum removal of $\mathrm{COD}_{\mathrm{Cr}}(91.6 \%)$ and colour $(94.5 \%)$ was obtained with $184 \mathrm{mg} \mathrm{L}^{-1} \mathrm{Fe}^{2+}$. However, further increase in the $\mathrm{Fe}^{2+}$ dose gave no further increase in removal efficiency, mainly through the $\bullet \mathrm{OH}$ being scavenged by the reaction with hydrogen peroxide and/or $\mathrm{Fe}^{2+}$ species as shown below: ${ }^{18}$

$$
\begin{aligned}
& \mathrm{H}_{2} \mathrm{O}_{2}+\bullet \mathrm{OH} \rightarrow \mathrm{HO}_{2}^{\bullet}+\mathrm{H}_{2} \mathrm{O} \\
& \bullet \mathrm{OH}+\mathrm{Fe}^{2+} \rightarrow \mathrm{Fe}^{3+}+\mathrm{OH}^{-}
\end{aligned}
$$

The $\mathrm{Fe}^{3+}$ formed can react with $\mathrm{H}_{2} \mathrm{O}_{2}$ as well as with $\bullet \mathrm{OH}$, regenerating the $\mathrm{Fe}^{2+}$ in solution, resulting in a decrease of the removal efficiency of $\mathrm{COD}_{\mathrm{Cr}}$ and colour. The scavenging effect of high doses of $\mathrm{Fe}^{2+}$ on ${ }^{\bullet} \mathrm{OH}$ radicals also contributed to the results in Fig. 5.

The concentrations of $\mathrm{F}^{-}, \mathrm{COD}_{\mathrm{Cr}}$, DOC, SS, and colour in the effluent from the Fenton oxidation/coagulation were $42 \mathrm{mg} \mathrm{L}^{-1}$, $172 \mathrm{mg} \mathrm{L}^{-1}, 78 \mathrm{mg} \mathrm{L}^{-1}, 60 \mathrm{mg} \mathrm{L}^{-1}$, and 20 (multiple) respectively, which satisfied the discharge and circulation limits for WCP.

Performance of continuous system and economic evaluation of this process

Design of the continuous pilot-scale system

Based on the batch study, a pilot-scale WCP treatment system with a capacity of $24 \mathrm{~m}^{3} \mathrm{~d}^{-1}$ was established and operated continuously for about 2 months to evaluate its feasibility for the treatment of WCP. Figure 1 shows a schematic of the system. The

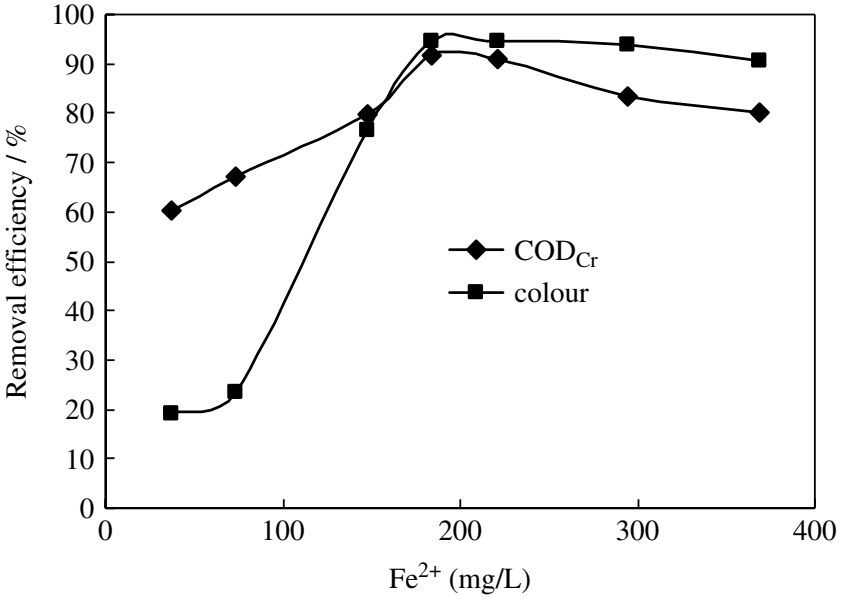

Figure 5. Effect of $\mathrm{Fe}^{2+}$ dosages on $\mathrm{COD}_{\mathrm{Cr}}$ and colour removal efficiency $\left(\mathrm{H}_{2} \mathrm{O}_{2}: 1500 \mathrm{mg} \mathrm{L}^{-1} ; \mathrm{pH} 3.5\right)$.

main operational parameters were: (1) chemical precipitation: lime slurry (10\%,w/w) $10 \mathrm{mg} \mathrm{L}^{-1}$, HRT $1 \mathrm{~h}$; (2) coagulation: HFS $1000 \mathrm{mg}$ $\mathrm{L}^{-1}$, HRT $1 \mathrm{~h}$; (3) equalization/acidification: HRT $3 \mathrm{~h}$; (4) Fenton oxidation: $\mathrm{Fe}^{2+} 184 \mathrm{mg} \mathrm{L}^{-1}, \mathrm{H}_{2} \mathrm{O}_{2} 1500 \mathrm{mg} \mathrm{L}^{-1}, \mathrm{HRT} 2 \mathrm{~h}, \mathrm{pH} 3.5$.

\section{Performance of the continuous system}

Table 2 shows the steady decrease in the levels of these pollutants from each unit process. Similar to the results of the batch scale study, the chemical precipitation and coagulation process led to high efficiency of $\mathrm{F}^{-}$and SS removal and Fenton oxidation significantly decreased the concentrations of $\mathrm{COD}_{\mathrm{Cr}}, \mathrm{DOC}$ and colour. The effluent concentrations of $\mathrm{F}^{-}, \mathrm{SS}, \mathrm{COD}_{\mathrm{Cr}}, \mathrm{DOC}$, and colour from the combined processes were: $38 \mathrm{mg} \mathrm{L}^{-1}, 44 \mathrm{mg} \mathrm{L}^{-1}$, $168 \mathrm{mg} \mathrm{L}^{-1}, 80 \mathrm{mg} \mathrm{L}^{-1}$, and 24 (multiple), respectively satisfying the discharge limits for the reusing system.

\section{Economic evaluation of this process}

The economic performance was evaluated based on the cost of chemical reagents used in this process (Table 3 ). The price of total reagents (US\$ per $\mathrm{m}^{3}$ ) is $2.661 \mathrm{US} \$ \mathrm{~m}^{-3} \cdot \mathrm{H}_{2} \mathrm{O}_{2}$ is the most expensive reagent and accounts for $53.7 \%$ of the total cost. Additionally, the cost of lime precipitation and primary coagulation is 0.558 US\$ $\mathrm{m}^{-3}$, and the Fenton oxidation and secondary coagulation is 2.103 US\$ $\mathrm{m}^{-3}$. The sludge generated in this process will be disposed of in the sludge disposal system of Guizhou Branch of the Aluminium Corporation of China and is only a very small addition to the disposal capacity. So sludge treatment and disposal was not considered in the economic evaluation. It should also be noted that the effluent from primary coagulation may be recycled as washing water to the washing tower, and the overall cost is acceptable in practice.

The results of the pilot scale study further demonstrated the feasibility of employing the combined process for the treatment of WCP in practice.

\section{CONCLUSIONS}

A combined WCP treatment system consisting of chemical precipitation, coagulation, and Fenton oxidation on a pilot-scale of $24 \mathrm{~m}^{3} \mathrm{~d}^{-1}$ was studied and the performance of the system measured for about 2 months. The results showed that the average 
Table 2. Pollutant reduction of WCP at each unit of combined system

\begin{tabular}{|c|c|c|c|c|c|c|c|}
\hline & \multicolumn{2}{|c|}{ Raw WCP } & \multicolumn{2}{|c|}{$\begin{array}{l}\text { Chemical } \\
\text { precipitation/coagulation }\end{array}$} & \multicolumn{2}{|c|}{$\begin{array}{c}\text { Fenton } \\
\text { oxidation/coagulation }\end{array}$} & \multirow{2}{*}{$\begin{array}{c}\begin{array}{c}\text { Total } \\
\text { removal }\end{array} \\
\text { efficiency \% }\end{array}$} \\
\hline & Range & Mean & Range & Mean & Range & Mean & \\
\hline Colour(multiple) & $1200-1600$ & 1400 & $300-600$ & 400 & $20-40$ & 24 & 98.3 \\
\hline $\mathrm{SS}\left(\mathrm{mg} \mathrm{L}^{-1}\right)$ & $3000-5000$ & 3530 & $77-156$ & 97 & $38-70$ & 44 & 98.8 \\
\hline $\operatorname{COD}_{\mathrm{Cr}}\left(\mathrm{mg} \mathrm{L}^{-1}\right)$ & $2500-4300$ & 3250 & $1800-3420$ & 1960 & $140-278$ & 168 & 94.8 \\
\hline $\mathrm{DOC}\left(\mathrm{mg} \mathrm{L}^{-1}\right)$ & $750-1200$ & 980 & $550-878$ & 730 & $65-148$ & 80 & 91.8 \\
\hline $\mathrm{F}^{-}\left(\mathrm{mg} \mathrm{L}^{-1}\right)$ & $600-1400$ & 880 & $88-167$ & 106 & $22-67$ & 38 & 95.7 \\
\hline
\end{tabular}

Table 3. Evaluation of the reagent cost for this process

\begin{tabular}{|c|c|c|}
\hline Chemical reagent and dosages & Price (US\$ $\mathrm{kg}^{-1}$ ) & Cost (US\$ $\mathrm{m}^{-3}$ ) \\
\hline Lime slurry $\left(10 \%, \mathrm{w} / \mathrm{w} ; 10 \mathrm{~kg} \mathrm{~m}^{-3}\right)$ & 0.043 & 0.430 \\
\hline $\mathrm{FeSO}_{4} \cdot 7 \mathrm{H}_{2} \mathrm{O}\left(1 \mathrm{~kg} \mathrm{~m}^{-3}\right)$ & 0.114 & 0.114 \\
\hline $\operatorname{PAM}\left(5 \mathrm{~g} \mathrm{~m}^{-3}\right)$ & 2.857 & 0.014 \\
\hline $\begin{array}{l}\text { Cost of lime precipitation and } \\
\text { primary coagulation }\end{array}$ & & 0.558 \\
\hline $\mathrm{H}_{2} \mathrm{O}_{2}(30 \%)\left(5 \mathrm{~kg} \mathrm{~m}^{-3}\right)$ & 0.286 & 1.430 \\
\hline $\mathrm{FeSO}_{4} \cdot 7 \mathrm{H}_{2} \mathrm{O}\left(0.9 \mathrm{~kg} \mathrm{~m}^{-3}\right)$ & 0.114 & 0.103 \\
\hline $\mathrm{H}_{2} \mathrm{SO}_{4}\left(5 \mathrm{~kg} \mathrm{~m}^{-3}\right)$ & 0.114 & 0.570 \\
\hline $\begin{array}{l}\text { Cost of the Fenton oxidation and } \\
\text { secondary coagulation }\end{array}$ & & 2.103 \\
\hline Total cost & & 2.661 \\
\hline
\end{tabular}

removal efficiencies of $\mathrm{F}^{-}, \mathrm{COD}_{\mathrm{Cr}}, \mathrm{DOC}, \mathrm{SS}$ and colour were $95.7 \%$. $94.8 \%, 91.8 \%, 98.8 \%$ and $98.3 \%$, respectively, with average effluent quality of $\mathrm{F}^{-} 38 \mathrm{mg} \mathrm{L}^{-1}, \mathrm{COD}_{\mathrm{Cr}} 168 \mathrm{mg} \mathrm{L}^{-1}$, DOC $80 \mathrm{mg} \mathrm{L}^{-1}$, SS $44 \mathrm{mg} \mathrm{L}^{-1}$ and colour 24 (multiple). The effluent quality was better than the standards for the reusing system established in the aluminium factory in Guizhou, Southwest China. From the results of the pilot-scale system and the cost evaluation, it can be concluded that the combined process can serve as an attractive solution for WCP treatment. Further research will focus on the mechanisms of the considerable synergistic effect on pollutants removal.

\section{REFERENCES}

$1 \mathrm{MaX}$, Kaneko T, XuG and Kato K, Influence of gas components on removal of $\mathrm{SO}_{2}$ from flue gas in the semidry $\mathrm{FGD}$ process with a powder-particle spouted bed. Fuel 80:673-680 (2001).

2 Jiang WY, Chai LY, Wang YY and Ouyang LW, Review on adsorption treatment of asphalt fume emitting from prebaked anode production process. Environ Pollut Control 27(9):692-695 (2005). (in Chinese with English abstract).

3 Klingspor J, Stroèmberg A, Karlsson HT and Bjerle I, Similarities between lime and limestone in wet-dry scrubbing. Chem Eng Process 18:239-247 (1984).

4 Deuster Ev, Mensing A, Jiang MX and Majdeski $\mathrm{H}$, Cleaning of flue gas from solid /waste incinerator plants by wet/semidry process. Environ Progress 13:149-53 (1994).

5 Gutiérrez FJ, Ollero P, Cabanillas A and Otero J, A technical pilot plant assessment of flue gas desulphurisation in a circulating fluidised bed. Adv Environ Res 7:73-85 (2002).

6 Gasthauer E, Mazé M, Marchand JP and Amouroux J, Characterization of asphalt fume composition by GC/MS and effect of temperature. Fuel 87:1428-1434 (2008).

7 Drouiche N, Ghaffour N, Lounici H, Mameri N, Maallemi A and Mahmoudi $\mathrm{H}$, Electrochemical treatment of chemical mechanical polishing wastewater: removal of fluoride-sludge characteristicsoperating cost. Desalination 223:134-142 (2008).
8 Eskandarpour A, Onyango MS, Ochieng A and Asai S, Removal of fluoride ions from aqueous solution at low $\mathrm{pH}$ using schwertmannite. J Hazard Mater 152:571-579 (2008).

9 Ndiaye PI, Moulin P, Dominguez L, Millet JC and Charbit F, Removal of fluoride from electronic industrial effluent by RO membrane separation. Desalination 173:25-32 (2005).

10 Shen F, Chen X, Gao P and Chen G, Electrochemical removal of fluoride ions from industrial wastewater. Chem Eng Sci 58:987-993 (2003).

11 Huang CJ and Liu JC, Precipitation flotation of fluoride-containing wastewater from semi-conductor manufacture. Water Res 33:3403-3412 (1999).

12 Toyoda A and Taira T, A new method for treating fluorine wastewater to reduce sludge and running costs. IEEE Trans Semiconduct Mater 13:305-309 (2000).

13 Reardon El and Wang YX, A limestone reactor for fluoride removal from wastewaters. Environ Sci Technol 34:3247-3253 (2000).

14 Bigda RJ, Consider Fenton's chemistry for wastewater treatment. Chem Eng Progress 91:62-66 (1995).

15 Bautista P, Mohedano AF, Casas JA, Zazo JA and Rodriguez JJ, An overview of the application of Fenton oxidation to industrial wastewaters treatment. J Chem Technol Biotechnol 83:1323-1338 (2008).

16 Meric S, Kaptan D and Olmez T, Colour and COD removal from wastewater containing Reactive Black 5 using Fenton's oxidation process. Chemosphere 54:435-441 (2004).

17 Wang XY, Zeng GM and Zhu JL, Treatment of jean-wash wastewater by combined coagulation, hydrolysis/acidification and Fenton oxidation. J Hazard Mater 153:810-816 (2008).

18 Benitez FJ, Acero JL, Real FJ, Rubio FJ and Leal Al, The role of hydroxyl radicals for the decomposition of $\mathrm{p}$-hydroxy phenylacetic acid in aqueous solutions. Water Res 35:1338-1343 (2001).

19 Pala A and Erden G, Decolourization of a baker's yeast industry effluent by Fenton oxidation. J Hazard Mater 127:141-148 (2005).

20 Kavitha $V$ and Palanivelu K, The role of ferrous ion in Fenton and photoFenton processes for the degradation of phenol. Chemosphere 55:1235-1243 (2004).

21 Comninellis C, Kapalka A, Malato S, Parsons SA, Poulios I and Mantzavinos D, Advanced oxidation processes for water treatment: advances and trends for R\&D.JChem Technol Biotechno/ 83:769-776 (2008).

22 Real FJ, Benitez FJ, Acero JL and Gonzalez M, Removal of diazinon by various advanced oxidation processes. J Chem Technol Biotechnol 82:566-574 (2007).

23 Gunale TL and Mahajani VV, Studies in mineralization of aqueous aniline using Fenton and wet oxidation (FENTWO) as a hybrid process. J Chem Technol Biotechnol 82:108-115 (2007).

24 Benitez FJ, Real FJ, Acero JL, Garcia C and Llanos EM, Kinetics of phenylurea herbicides oxidation by Fenton and photo-Fenton processes. J Chem Technol Biotechnol 82:65-73 (2007).

25 Chetia B and lyer PK, Utilization of 2,6-bis(2-benzimidazolyl)pyridine to detect toxic benzene metabolites. Tetrahedron Lett 48:47-50 (2007).

26 Wannalerse B, Tuntulani T and Tomapatanaget B, Synthesis, optical and electrochemical properties of new receptors and sensors containing anthraquinone and benzimidazole units. Tetrahedron 64:10619-10624 (2008).

27 Tekin H, Bilkay O, Ataberk SS, Balta TH, Ceribasi H, Sanin FD, et al, Use of Fenton oxidation to improve the biodegradability of a pharmaceutical wastewater. J Hazard Mater B136:258-265 (2006). 